\title{
Safety of users in road evacuation: calibration of cost functions and simulation
}

\author{
A. Vitetta, G. Musolino \& F. A. Marcianò \\ LAST - Laboratory for Transport Systems Analysis, \\ DIMET - Department of Computer Science, Mathematics, Electronics \\ and Transportation, Mediterranea University of Reggio Calabria, Italy
}

\begin{abstract}
Advancements regarding Dynamic Traffic Assignment (DTA) microscopic models for the simulation of supply and demand-supply interaction of a road transportation system in emergency conditions are presented. They are related to link and node models specified in the research project SICURO, carried out by the Laboratory for Transport Systems Analysis (LAST) of the Mediterranea University of Reggio Calabria (Italy). Microscopic link (car-following) and gap-acceptance (rejection) models for non-signalized intersections are calibrated from data observed during a real simulation of evacuation. An application is performed in order to reproduce the observed evacuation phases through a set of performance indicators.
\end{abstract}

Keywords: evacuation, cost functions, microscopic models.

\section{Introduction}

The paper presents advancements regarding Dynamic Traffic Assignment (DTA) microscopic models specified in the research project SICURO carried out by the Laboratory for Transport Systems Analysis (LAST) of the Mediterranea University of Reggio Calabria (Italy).

Static assignment models [1] are not able to simulate supply and demandsupply interaction of a road transportation system in emergency conditions when temporary over-saturation of some transportation supply elements, queue formation and dispersion occur. In this context, DTA models and procedures become necessary. They have different specifications: pseudo-dynamic, mesoscopic and microscopic [2-5]. 
Microscopic link and node models able to simulate supply and supplydemand interaction of a road transportation system in emergency conditions are presented. Model parameters are calibrated from data observed during a real simulation of evacuation executed at the test site of Melito Porto Salvo (Italy).

From previous works related to research project SICURO [4,5], advancements concern:

- $\quad$ literature review on DTA models in emergency conditions;

- $\quad$ calibration of a microscopic link model (car-following) and node model (gap-acceptance/rejection model);

- $\quad$ simulation of evacuation phases observed during the real simulation conducted at the test site of Melito Porto Salvo (Italy).

The paper is structured into five sections. In section 2 the literature review concerning DTA models in emergency conditions is presented. In section 3 the microscopic models used are specified. Section 4 describes data acquisition and presents calibrated model parameters. Section 5 reports the application performed in order to reproduce the observed evacuation. In conclusion, future research is highlighted.

\section{Literature review of DTA models in emergency conditions}

While the literature concerning DTA procedures for demand-supply interaction simulation of road transportation systems in ordinary conditions is extensive $[4,5]$, DTA procedures in emergency conditions have received less attention.

Models for transportation systems analysis in emergency conditions were developed in USA after the partial meltdown of the reactor at the Three Mile Island nuclear power plant in 1979. In the 1980s a first generation of models for simulating evacuation phases was developed. They differ according to the adopted approach: macroscopic, mesoscopic or microscopic. Each approach presents some limitations in evacuation phase simulation. Macroscopic models were unable to simulate traffic flow in emergency conditions (queue creation and dissipation) while microscopic models, whilst able to represent each individual behaviour, could not be used on real networks due to computational limitations. Therefore, mesoscopic models represented a good compromise at that time.

After $9 / 11$, research on transportation systems in emergency conditions received a new stimulus and a second generation of models was developed. The increasing computational burdens allowed the use of microscopic and mesoscopic simulation models also on wide networks for transportation systems simulation in emergency conditions.

DTA procedures for emergency conditions can be distinguished according to purpose (simulation of plan, demand or supply design), study area (building, urban area, industrial area) and adopted approach (macroscopic, microscopic or mesoscopic).

Many researchers have used traffic simulation models to evaluate the effectiveness of different emergency operation plans both for urban and industrial areas [14], under different approaches, whether macroscopic [6,7], microscopic [8-10], or mesoscopic [11-13]. 
Demand management applications concern departure times in order to delay congestion phenomena and minimize evacuation time. Several demand time profiles are defined and simulated through mesoscopic [15] or microscopic simulators [16] and compared with the simultaneous departures scenario. Evacuation demand scheduling is also treated through a pseudo-dynamic approach [2]. As regards industrial plant, KLD has carried out research into demand management for the evacuation of nuclear plants [17,18] and arms depot [19].

Supply design concerns path optimization and management in emergency conditions [20]. As regards path optimization design, there are several applications related both for buildings [21,22] and urban areas [23].

Recently, attention has focused on supply management through some actions like contraflow operations [24-26] and ramp metering $[10,27,28]$ in order to improve network capacity during evacuation.

\section{Models}

The specified car-following model is a relationship between speed, $\mathrm{v}$, and density, $\mathrm{k}$. Model parameters are functions of five link attributes: free speed, $\mathrm{v}_{0}$; speed at capacity, $\mathrm{v}_{\mathrm{CR}}$; capacity, $\mathrm{C}$; jam density, $\mathrm{k}_{\mathrm{J}}$; link available width, $\mathrm{L}$.

The car-following model has the following equation:

$$
\begin{aligned}
\mathrm{v}= & \left(\left(\left(\alpha_{3} \mathrm{v}_{0}-\alpha_{4}\right) \mathrm{k}+1\right)+\left(\left(\left(\alpha_{3} \mathrm{v}_{0}-\alpha_{4}\right) \mathrm{k}+1\right)^{2}+\right.\right. \\
& \left.\left.+4\left(\alpha_{3} \mathrm{k}\right)\left(\left(\alpha_{4} \mathrm{v}_{0}+\alpha_{2}\right) \mathrm{k}-\mathrm{v}_{0}\right)\right)^{0.5}\right) / 2 \alpha_{3} \mathrm{k}
\end{aligned}
$$

where

$$
\begin{aligned}
\alpha_{1} & =\left(2 \mathrm{v}_{\mathrm{CR}}-\mathrm{v}_{0}\right) /\left(\mathrm{v}_{0}-\mathrm{v}_{\mathrm{CR}}\right)^{2} \\
\alpha_{2} & =\left(1 / \mathrm{k}_{\mathrm{J}}\right)\left[1 /\left(\alpha_{4}+1 / \mathrm{v}_{0}\right)\right] \\
\alpha_{3} & =\left[-\alpha_{1}+\mathrm{v}_{0} / \mathrm{C}-\left(\alpha_{2} /\left(\mathrm{v}_{0}-\mathrm{v}_{\mathrm{CR}}\right)\right)\right] / \mathrm{v}_{\mathrm{CR}} \\
\alpha_{4} & =\alpha_{1} \alpha_{2}
\end{aligned}
$$

with parameters $\alpha_{1}, \alpha_{2}, \alpha_{3}$ and $\alpha_{4}$ to be calculated for each link where $v_{0}, v_{\mathrm{CR}}, \mathrm{C}$ and $\mathrm{k}_{\mathrm{J}}$ are known. They can be expressed through the following equations:

$$
\begin{aligned}
& \mathrm{k}_{\mathrm{J}}=\beta_{1} \\
& \mathrm{v}_{0}=\beta_{2} \mathrm{~L} \\
& \mathrm{v}_{\mathrm{CR}}=\beta_{3} \mathrm{v}_{0} \\
& \mathrm{C}=\beta_{4} \mathrm{~L}
\end{aligned}
$$

with parameters $\beta_{1}, \beta_{2}, \beta_{3}$ and $\beta_{4}$ to be calibrated.

The gap-acceptance (rejection) model is deterministic and represents a relationship between the accepted (rejected) gap, $\mathrm{G}$, and waiting time, $\mathrm{t}_{\mathrm{w}}$. It has the following equation:

$$
G(\mathrm{t})=\beta_{5}+\beta_{6} \mathrm{t}_{\mathrm{w}}
$$

with parameters $\beta_{5}$ and $\beta_{6}$ to be calibrated.

\section{Experimentation}

In the context of the research project, a real simulation of evacuation in the experimental test site of Melito Porto Salvo (Reggio Calabria, Italy) was organized and executed. It allowed data to be obtained for model calibration. 


\subsection{Data acquisition}

Evacuation of population with motorized modes was filmed through a system of video cameras located on some selected links and nodes of the road network. The following traffic flow data were extracted in the laboratory from traffic scene analysis:

- $\quad$ vehicle speed, traffic flow and density on links;

- $\quad$ accepted gap, rejected gap and waiting time at nodes.

Vehicle speeds and densities were estimated for three selected road links with different available widths $(3.5 \mathrm{~m}, 4.0 \mathrm{~m}$ and $5.0 \mathrm{~m}$ respectively). Accepted and rejected gaps and waiting times were observed on a selected non-signalized intersection. Data were related to uncongested and congested traffic flow conditions. Further details are reported in [4] and [5].

\subsection{Model calibration and validation}

Estimated and observed variables were used, respectively, to calibrate the carfollowing model reported in eqn (1), whose parameters are reported in eqns (6), (7), (8) and (9), and the gap-acceptance (rejection) model reported in eqn (10). Parameter calibration was carried out with the Least Squares Method, while validation was executed through informal tests on calibrated parameter signs and statistical indicators MSE and RMSE \%. Further details are reported in [4] and [5].

Table 1 presents the calibrated parameters of the car-following model and statistical indicators.

Table 1: $\quad$ Calibrated parameters of the car-following model.

\begin{tabular}{cccccc}
\hline $\begin{array}{c}\beta_{1} \\
(\text { vehic } / \mathrm{km})\end{array}$ & $\begin{array}{c}\beta_{2} \\
(\mathrm{~km} /(\mathrm{h} \mathrm{m}))\end{array}$ & $\beta_{3}$ & $\begin{array}{c}\beta_{4} \\
(\text { vehic/(h m) })\end{array}$ & MSE & RMSE \% \\
\hline 180 & 7.50 & 0.85 & 317.00 & 30.09 & 19.37 \\
\hline
\end{tabular}

In table 2 link attributes (free-flow speed, $\mathrm{v}_{0}$; critical speed, $\mathrm{v}_{\mathrm{CR}}$; jam density, $\mathrm{k}_{\mathrm{J}}$; capacity, C) related to the three selected links with different link available width, L, and MSE and RMSE\% are reported.

The gap-acceptance (rejection) model was calibrated for straight-through and right-turn manoeuvres. Table 3 presents the calibrated parameters of the gapacceptance model and statistical indicators. Table 4 presents the values of parameters of the gap-rejection model, estimated through geometrical considerations.

In figures 1 and 2 calibrated gap-acceptance (rejection) models are depicted for the two types of manoeuvre. The figures show the reduction of accepted and rejected gaps for increasing waiting times. Moreover, the accepted gap at $t_{w}=0$ is more than 2 seconds greater for straight-through manoeuvres than for right turns. This result is confirmed for the rejected gap and means that right-turn manoeuvres are less complex and require the presence of a lower gap than straight-through manoeuvres. 
Table 2: $\quad$ Link attributes and statistical indicators.

\begin{tabular}{ccccc}
\hline \multirow{2}{*}{$\begin{array}{c}\text { Attribute/ } \\
\text { Statistics }\end{array}$} & \multirow{2}{*}{ Unit of measure } & \multicolumn{3}{c}{ Link available width (L) } \\
\cline { 3 - 5 } & & $\mathrm{L}=3.5 \mathrm{~m}$ & $\mathrm{~L}=4.0 \mathrm{~m}$ & $\mathrm{~L}=5.0 \mathrm{~m}$ \\
\hline $\mathrm{v}_{0}$ & $(\mathrm{~km} / \mathrm{h})$ & 26.3 & 30.0 & 37.5 \\
$\mathrm{v}_{\mathrm{CR}}$ & $(\mathrm{km} / \mathrm{h})$ & 22.3 & 25.5 & 31.9 \\
$\mathrm{k}_{\mathrm{J}}$ & $($ vehic $/ \mathrm{km})$ & 180 & 180 & 180 \\
$\mathrm{C}$ & $(\mathrm{vehic} / \mathrm{h})$ & 1110 & 1269 & 1586 \\
$\mathrm{MSE}$ & $/ /$ & 13.30 & 16.53 & 52.66 \\
$\mathrm{RMSE} \%$ & $/ /$ & 20.39 & 23.68 & 24.61 \\
\hline
\end{tabular}

Table 3: $\quad$ Calibrated parameters of the gap-acceptance model.

\begin{tabular}{lcccc}
\hline \multicolumn{1}{c}{ Manoeuvre } & $\begin{array}{c}\beta_{5} \\
(\mathrm{sec})\end{array}$ & $\boldsymbol{\beta}_{6}$ & MSE & RMSE \% \\
\hline Straight-through & 8.432 & -0.422 & 0.92 & 16.19 \\
\hline Right turn & 6.436 & -0.332 & 0.92 & 16.19 \\
\hline
\end{tabular}

Table 4: $\quad$ Estimated parameters of the gap-rejection model.

\begin{tabular}{lllll}
\hline \multicolumn{1}{c}{ Manoeuvre } & $\begin{array}{c}\beta_{5} \\
(\mathrm{sec})\end{array}$ & $\beta_{6}$ & MSE & RMSE \% \\
\hline Straight-through & 2.27 & -0.11 & -- & -- \\
\hline Right turn & 1.57 & -0.08 & -- & -- \\
\hline
\end{tabular}



Figure 1: Gap-acceptance and gap-rejection models (straight-through manoeuvres).

\section{Application}

A computer application was performed to reproduce evacuation observed at the test site of Melito di Porto Salvo. 


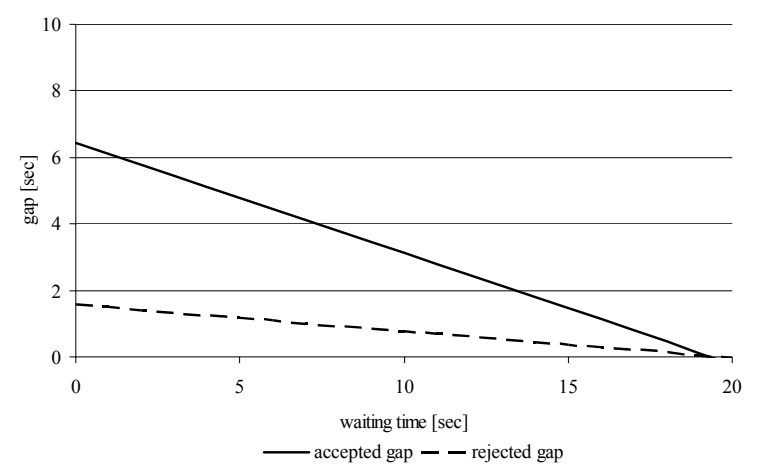

Figure 2: Gap-acceptance and gap-rejection models (right-turn manoeuvres).

The time schedule concerning a generic event's occurrence is characterized by five instants:

- $\mathrm{t}_{0}$, instant when the emergency planning activities start;

- $\mathrm{t}_{1}$, instant when the occurrence of forthcoming disaster is notified or supposed forecasted;

- $\quad t_{2}$, instant when the event occurs, becomes a disaster and starts its effects;

- $\quad t_{3}$, instant when the final effect occurs and people cannot be rescued;

- $t_{4}$, instant when the event ceases its direct effects on the system.

The simulation of demand-supply interaction required the evolution of demand and supply to be schematized. Demand is divided into historical demand and evacuation demand, supply into unmodified supply and modified supply. In terms of demand-supply interaction the transport system can be in ordinary conditions or in emergency conditions. Referring to the characteristic five instants, the system is in emergency conditions between $t_{1}$ and $t_{4}$. Further details are reported in [4] and [5].

Let $t_{\mathrm{A}}$ and $t_{\mathrm{P}}$ be, respectively, the departure time of the first evacuated vehicle and the arrival time of the last evacuated vehicle. The emergency conditions can be divided into:

- $\quad$ pre-evacuation conditions, between $\mathrm{t}_{1}$ and $\mathrm{t}_{\mathrm{A}}$, given by historical demandunmodified/modified supply interaction;

- evacuation conditions, between $\mathrm{t}_{\mathrm{A}}$ and $\mathrm{t}_{\mathrm{P}}$, given by historical plus evacuation demand- unmodified/modified supply interaction;

- $\quad$ post-evacuation conditions, between $t_{p}$ and $t_{4}$, given by historical demandunmodified/modified supply interaction.

Figure 3 shows phases of the observed evacuation in the test site of Melito di Porto Salvo (Italy). The simulation was divided into five periods representing the transport system conditions previously defined. Further details are reported in [4] and [5].

Some transportation network performance indicators were estimated. They can be divided into demand-supply interaction indicators and evolution indicators. 
Table 5 reports the values of the demand-supply interaction indicators for each phase considered. The most significant is vehicle evacuation time, $T_{e v}$, of 1260 seconds (about 21 minutes). Moreover, from the comparison of the five periods, it can be observed that the transition from unmodified supply to modified supply implies a reduction in network performances. For example, the average speed decreases by $12.7 \%$ while the average travel time per vehicle increases by $28.2 \%$.

In figure 4 the time profile of the number of vehicles that reach the refuge area is reported. Initially, it has a growing trend with a peak at 10:50 a.m., about 15 minutes after the evacuation starts. At each instant, the time profile provides the number of vehicles rescued. If $t *$ is a generic instant, the sum of vehicles that reach the refuge area in the following instants, $t>t^{*}$, represents the exposure of the system at $t^{*}$.

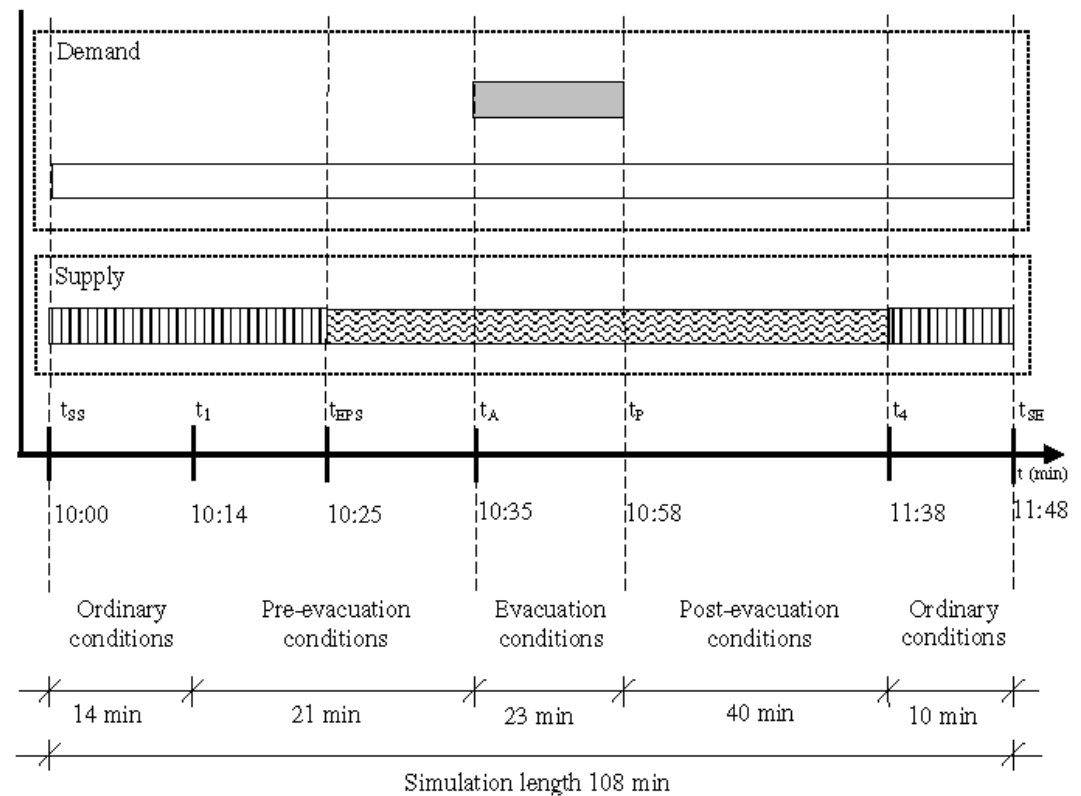

$\begin{array}{ccc}\square \text { Historical demand } \\ \mathrm{t}_{\text {SS }} \text { simulation starts } \\ \text { Evacuation demand } & \mathrm{t}_{\text {EPS }} \text { evacuation procedures start } & \mathrm{t}_{\text {SE }} \text { Simulation ends }\end{array}$

Figure 3: Phases of observed evacuation.

\section{Conclusions and prospects}

The paper presents advancements concerning microscopic models specified in the research project entitled SICURO carried out by the Laboratory for Transport Systems Analysis (LAST) of the Mediterranea University of Reggio Calabria (Italy). From previous work, advancements concerns the calibration of a 
microscopic link model (car-following) and a gap-acceptance (rejection) model for non-signalized intersections. They were calibrated from data observed during a real simulation of evacuation carried out at the test site of Melito Porto Salvo (Italy). Models are able to simulate transport supply and demand-supply interaction when a population has to be evacuated due to a forthcoming disaster. A computer application was performed in order to reproduce the observed evacuation phases.

Table 5: $\quad$ Demand-supply interaction indicators.

\begin{tabular}{cccrrrr}
\hline \multirow{2}{*}{$\begin{array}{c}\text { System } \\
\text { conditions }\end{array}$} & \multirow{2}{*}{ Demand } & Supply & \multicolumn{4}{c}{ Indicator } \\
\cline { 4 - 7 } & & & $\mathrm{L}_{\mathrm{a}}$ & $\mathrm{T}_{\mathrm{a}}$ & $\mathrm{T}_{\mathrm{ev}}$ & $\mathrm{V}_{\mathrm{a}}$ \\
\hline Ordinary & Historical & Unmodified & 1.06 & 127.8 & $/ /$ & 31.4 \\
\hline \multirow{2}{*}{ Pre-evacuation } & Historical & Unmodified & 1.06 & 127.8 & $/ /$ & 31.4 \\
\cline { 2 - 7 } & Historical & Modified & 1.31 & 163.8 & $/ /$ & 27.4 \\
\hline \multirow{2}{*}{ Evacuation } & Historical & Modified & 1.31 & 163.8 & $/ /$ & 27.4 \\
\cline { 2 - 7 } & Evacuation & Modified & 1.96 & 300.6 & 1260 & 25.5 \\
\hline Post-evacuation & Historical & Modified & 1.31 & 163.8 & $/ /$ & 27.4 \\
\hline Ordinary & Historical & Unmodified & 1.06 & 127.8 & $/ /$ & 31.4 \\
\hline
\end{tabular}

$\mathrm{L}_{\mathrm{a}}=$ average travel distance per vehicle $(\mathrm{km}) ; \mathrm{T}_{\mathrm{a}}=$ average travel time per vehicle (sec);

$\mathrm{T}_{\mathrm{ev}}=$ evacuation time $(\mathrm{sec}) ; \mathrm{V}_{\mathrm{a}}=$ average speed on the network $(\mathrm{km} / \mathrm{h})$

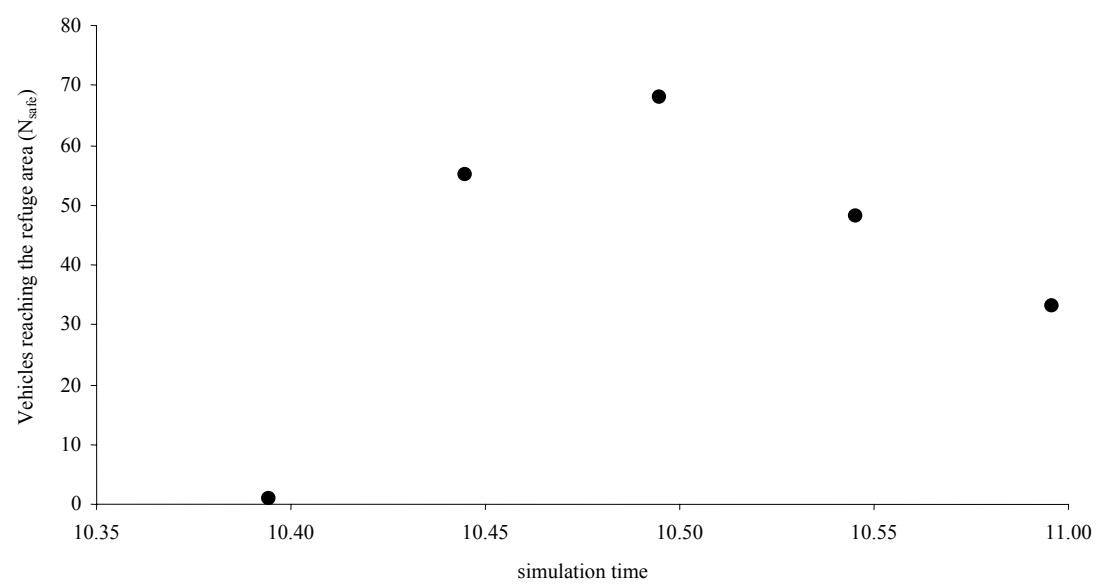

Figure 4: Time profile of the number of vehicles reaching the refuge area.

Possible future developments concern model calibration for other types of roads (in extra-urban areas) and the performance of simulation over wider urban areas. 


\section{Acknowledgement}

Partially supported by Regione Calabria (EU Structural Fund 2000-2006) in the framework of the SICURO project (note no. 19193 of November 23, 2004, on the implementation of measure 3.16 action 3.1.a.3).

\section{References}

[1] Russo, F., Vitetta, A., An assignment model with modified Logit, which obviates enumeration and overlapping problems, Transportation, vol. 30, pp. 177-201, 2003.

[2] Velonà, P., Vitetta, A., Evolution of an urban transportation system in emergency conditions: analysis through a pseudo-dynamic assignment model. In Environmental Health Risk II, C. A. Brebbia, D. Fayziera (eds.), WIT Press, Boston, pp. 217-226, 2003.

[3] Di Gangi, M. \& Velonà, P., Use of a mesoscopic dynamic assignment model for approaching the evolution of an urban transportation system in emergency conditions. In Environmental Health Risk II, C. A. Brebbia, D. Fayziera (eds.), WIT Press, Boston, pp. 227-236, 2003.

[4] Vitetta, A. Musolino, G. \& Marcianò, F. A., Safety of users in road evacuation: supply and demand-supply interaction models for users. In Urban Transport: Safety of Users in Road Evacuation. Russo F. (ed.), WIT Press, pp. 21-30, 2007. ISBN 978-1-84564-139-9.

[5] Vitetta, A., Musolino, G., Marcianò, F. A., Offerta e interazione tra domanda e offerta nei sistemi di trasporto in condizioni di emergenza. Modelli e metodi per la simulazione, applicazione ad un caso reale. FrancoAngeli, Milan, 2007. ISBN: 978-88-464-9064-3.

[6] Sheffi, Y., Mahmassani, H., Powell, W. B., A transportation network evacuation. In Transportation Research A, Vol. 16A, 3, pp. 209-218, 1982.

[7] Avkowitz, M., Meyer, E., Technological advancements in hazardous materials evacuation planning. In Transportation Research Record (1552), Transportation Research Board, Washington, DC, pp. 116-121, 1996.

[8] Moeller, M.P., Urbanik, T., Desrosiers, A.E., CLEAR (Calculated Logical Evacuation And Response): a generic transportation network model for the calculation of evacuation time estimates. Prepared for the Nuclear Regulatory Commission by Pacific Northwest Laboratory. NUREG/CR2504. Washington DC, 1981.

[9] Cova, T. J., Johnson, J. P., Microsimulation of neighborhood evacuations in the urban-wildland interface. In Environ. Plan. B: Plan. Des., 34, pp. $2211-$ 2229, 2002.

[10] McGhee, C.C., Grimes, M.C., An operational analysis of the Hampton roads hurricane evacuation traffic control plan. In TRB Annual Meeting, 2007.

[11] Kwon, E., Pitt, S., Evaluation of emergency evacuation strategies for downtown event traffic using a dynamic network model. In Transportation Research Record (1922), Transportation Research Board, Washington, DC, pp. 149-155, 2005. 
[12] Di Gangi, M., Luongo, A., Polidoro, R., Una procedura di carico dinamico per la valutazione dei piani di evacuazione. In Metodi e Tecnologie dell'Ingegneria dei Trasporti. Seminario 1999, G.E. Cantarella and F. Russo (eds.), FrancoAngeli. Milan, 2001.

[13] Di Gangi, M., Velonà, P., Analisi e gestione di una rete di trasporto in condizioni di emergenza mediante procedure di mesosimulazione. In: Evacuazione dei sistemi urbani. In Metodi quantitativi per l'analisi di un sistema di trasporto in condizioni di emergenza (ed.) F. Russo, pp. 107128. FrancoAngeli, Milan. ISBN 88-464-5348-4, 2004.

[14] Jha, M., Moore, K., Pashaie, B., Emergency evacuation planning with microscopic traffic simulation. In Transportation Research Record (1886), Transportation Research Board, Washington, D.C., pp. 40-48, 2004.

[15] Sbayti, H., Mahmassani, H. S., Optimal scheduling of evacuation operations. In Transportation Research Record (1964), Transportation Research Board, Washington, D.C., pp. 238-246, 2006.

[16] Mitchell, S.W., Radwan, E., Heuristic prioritization of emergency evacuation staging to reduce clearance time. In TRB Annual Meeting, 2006.

[17] Goldblatt, R., Evacuation Time Estimate Study for the Kuosheng Nuclear Power Station. In Transportation Research, 237, 1990.

[18] Goldblatt, R., Lieberman, E., Development of Evacuation Time Estimates For the Waterford 3 Nuclear Power Station. In Transportation Research (283), 1993.

[19] Goldblatt, R., Development of Evacuation Time Estimates for the Pine Bluff Arsenal. In Transportation Research, 329, 1997.

[20] Russo, F., Vitetta, A., Urban road transportation analysis in emergency conditions: models and algorithms. In Proceedings of Urban Transport 2000, Wessex Institute of Technology. Sucharov and Brebbia (eds.), WIT Press Boston, pp. 533-542, 2000

[21] Di Gangi, M., Velonà, P., Deflusso pedonale negli edifici in condizioni di emergenza. In Modelli e metodi per la simulazione, applicazione ad un caso reale. FrancoAngeli, Milan, 2007.

[22] Sisiopiku, V. P., Johes, S. L., Sullinan, A. J., Patharkar, S. S., Tang, X., Regional traffic simulation for emergency preparedness. In UTCA Report 03226, University Transportation Center for Alabama, 2004.

[23] Cova, T. J., Johnson, J. P., A network flow model for lane-based evacuation routing. In Transportation Research Part A, Vol. 37A, pp. 257-275, 2003.

[24] Dong, Z., Xue, D., Intelligent scheduling of contraflow control operation using hierarchical pattern recognition and constrained optimization. In IEEE, pp. 135-140, 1997.

[25] Theodoulou, G., Wolshon, B., Alternative methods to increase the effectiveness of freeway contraflow evacuation. In Transportation Research Record (1865), Transportation Research Board, Washington, D.C., pp. 48-56, 2004.

[26] Tuydes, H., Ziliaskopoulos, A., Tabu-based heuristic approach for optimization of network evacuation contraflow. In Transportation Research 
Record (1964), Transportation Research Board, Washington, D.C., pp. 157-168, 2006.

[27] Gomes, G., May, A., A microsimulation of a congested freeway using VISSIM. In TRB Annual Meeting, 2004.

[28] Wiedmann, R., Modeling of RTI-elements on multi-lane roads. In Advanced Telematic in Road Transport, 1991. 